\title{
The potential for energy self-sufficiency in the United Kingdom rendering industry
}

\author{
A. D. Ramirez ${ }^{1}$, A. Humphries ${ }^{1}$, S. L. Woodgate $^{2} \&$ R. Wilkinson ${ }^{1}$ \\ ${ }^{1}$ Harper Adams University College, UK \\ ${ }^{2}$ Foodchain and Biomass Renewables Association Limited, UK
}

\begin{abstract}
Animal by-products (ABPs) are co-products of meat production system that include on-farm fallen stock and slaughterhouse co-products that are not fit for human consumption (different types of fat, offal and bone). Slaughterhouse coproducts represent between 30 to $50 \%$ of the life weight of farm animals. In the UK, fat, offal and bone are normally handled by rendering. Rendering is a process where $\mathrm{ABP}$ are sized and then dried to produce rendered products: tallow and a protein meal. Depending on the category of the ABP, rendered products can be used in pet foods manufacturing, the oleochemical industry and as biofuels (with and without further processing). The UK rendering industry uses both tallow and natural gas as fuel for heat production during the drying process. A study of UK rendering plants was undertaken to determine the total tallow production and the relative proportions of tallow and natural gas used as fuels. Data on fuel and energy use was collected from five rendering plants, representing $50 \%$ of the ABP processed in the UK. The results indicate that tallow use by the UK rendering industry ranged from $15-100 \%$ of total heat production with the remainder being derived from natural gas. When scaled up, it can be calculated that between 2006 and 2008 the UK rendering industry required around 5.7 PJ of heat per annum. During the same period the energy potentially available from rendered tallow (usable as biofuel) was 6.7 PJ. It can be concluded that potentially the UK rendering industry could be self-sufficient in energy use. However, use of tallow as a biofuel depends on the relative cost of natural gas compared to alternative markets for tallow.
\end{abstract}

Keywords: rendering, self-sufficiency, tallow, meat and bone meal, biofuels, United Kingdom. 


\section{Introduction}

The rendering industry is accepted to play an important role in the sustainable food chain by transforming animal by-products (ABPs) into processed proteins in form of the Meat and Bone Meal (MBM) and Processed Animal Proteins (PAP) and rendered fats (tallow). These ABPs provide feedstock material for other industries that include pet food manufacturing, the oleochemical industry and the biofuel industry. ABPs are secondary products of the animal agriculture and meat industries. ABPs include hides, skins, hairs, feathers, hoofs, horns, feet, heads, bones, toe nails, blood, organs, glands, intestines, muscle and fat tissues, shells and whole carcasses (Meeker and Hamilton [4]).

ABPs and their final uses are classified into 3 categories according to European Legislation [1]. Category 1 material includes animals infected or suspected of infection with a Transmissible Spongiform Encephalopathy, Specified Risk Material (SRM) which in the UK includes entire head, vertebral column, tonsils, spinal cord and intestines of ruminants, and entire bodies containing SRM. Category 1 materials must be destroyed by combustion or rendering. Category 1 rendered products can be used as biofuels. Category 2 materials are mostly on-farm mortalities, manure and digestive tract content. Category 2 rendered fats can be used in the oleochemical industry and for the production of fertilizers. MBM can be used as fertilizer or anaerobically digested to produce biogas. Category 3 materials are ABPs that are fit for human consumption or unfit but with no transmissible diseases. The final use of this material, besides those detailed for category 1 and 2 , is as raw material for pet food manufacturing. When different category materials are mixed together they are classified as the lower category in the mix [1]. Normally in the UK, category 1 and 2 materials are mixed together and treated as category 1 materials.

According to Woodgate [7] the UK rendering industry processed over 2 million $\mathrm{Mg}$ of ABP between per annum between 2006 and 2008. The various uses for rendered protein and fat are presented in figures 1 and 2 respectively. Combustion as a fuel is the most important use for category 1 rendered fats. They are normally used as fuels for boilers in rendering plants. Biodiesel production is also an important use for every category of rendered fats [7].

Rendering is an energy intensive process that involves both physical and chemical transformation, with the processes involving particle size reduction, heat treatment (for dehydration and microbial sterilization), pressing, separation and milling. The combustion of fossil fuels mainly associated with energy use is the most important source of carbon dioxide (Woodgate and van der Veen [8]).

The objective of this study was to estimate the consumption of energy by the UK rendering industry. Further objectives of the study were to estimate the percentage use of self-produced tallow by the UK rendering industry, and to analyse whether the UK rendering industry could be energy self-sufficient. 


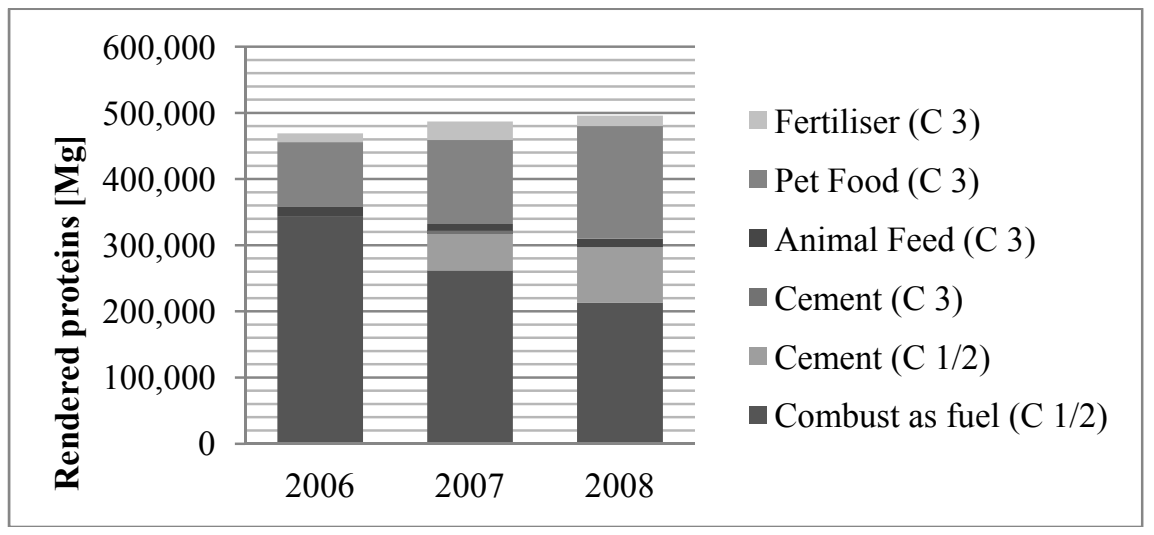

Figure 1: $\quad$ Uses of rendered proteins in the UK between 2006 and 2008 [7].

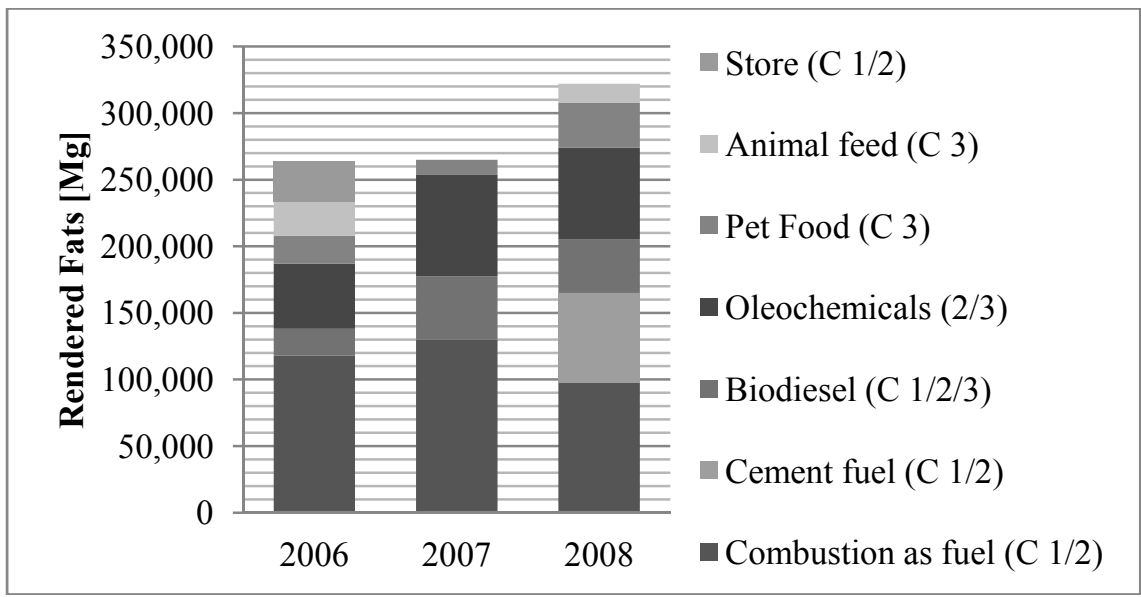

Figure 2: $\quad$ Uses of rendered fats in the UK between 2006 and 2008 [7].

\section{Methodology}

\subsection{Energy consumption in the UK rendering industry}

Data from six UK rendering plants were collected directly through the completion of a structured questionnaire. Data was collected for the years 2006, 2007, and 2008. Specific data collected were ABP yield, the amount of energy consumed (i.e. electricity, tallow, and natural gas), and the energy content of tallow and MBM.

The yield of protein meals and tallow produced by each rendering plant in each of the three years studied was gathered. Yield is defined as the percentage (in mass) of ABP converted to rendered product, and can be considered indicative of the water content of the ABP to be processed. For example, the 
higher the water content of the ABP to be processed, the lower the yield due to the evaporation of water during the rendering process (i.e. mass is lost from the system).

The energy released from the combustion of fuel (natural gas or tallow) by the rendering plants studied was calculated using the gross calorific value of the fuel (Table 1) and multiplying it by the annual amount of fuel used by each plant (Equation (1)). Combustion efficiency was ignored as the purpose of the study was to estimate the energy used in fuels. The annual amount of fuel used was obtained directly from the plants records.

Table 1: $\quad$ Gross calorific value of fuels.

\begin{tabular}{|c|c|c|}
\hline Fuel & GCV $(\mathrm{MJ} / \mathrm{kg})$ & Source \\
\hline Tallow & 39 & Provided by plants \\
\hline Natural gas & 54 & NPL [5] \\
\hline
\end{tabular}

The expression to calculate the (annual) heat energy use is:

$$
E_{\text {heat } x}=m_{\text {fuel } x} \times G C V_{\text {fuel } x}
$$

where

$E_{\text {heat } x}$ is the energy contained in the fuel $x$,

$m_{\text {fuel } x}$ is the mass of fuel $x$ and,

$G C V_{\text {fuel } x}$ is the gross calorific value of fuel $x$ (see Table 1).

The annual amount of electricity consumed by each plant was obtained directly from records regarding the annual amount of electricity purchased.

\subsection{Potential for energy self-sufficiency in the UK rendering industry}

To estimate the annual amount of energy consumed for thermal energy production $\left(E_{\text {thermal-required }}\right)$ by the UK rendering industry, the average amount of energy consumed by the six plants examined in the current study $\left(h_{\text {rendering }}\right.$ $\mathrm{MJ} / \mathrm{kg} \mathrm{ABP}$ ) was multiplied by the annual mass of ABP processed by the UK rendering industry ( $\left.m_{A B P-\text { procesed }}\right)$ according to Equation (2).

The amount of thermal energy that could be produced by the UK rendering industry $\left(E_{\text {thermal-potential }}\right)$ from the combustion of tallow was calculated from the amount of category 1 tallow produced annually ( $\left.m_{\text {cat } 1 \text { tallow-avai }}\right)$ according to Equation (3). The potential for the UK rendering industry to be self-sufficient in terms of thermal energy demand was expressed as a ratio, referred to as the thermal self-sufficiency ratio ( $\left.S S R_{\text {thermal }}\right)$, Equation (4).

$$
\begin{gathered}
E_{\text {thermal-required }}=m_{A B P-\text { procesed }} h_{\text {rendering }} \\
E_{\text {thermal-potential }}=m_{\text {cat1tallow-avai }} G C V_{\text {tallow }}
\end{gathered}
$$




$$
S S R_{\text {thermal }}=\frac{E_{\text {thermal-potential }}}{E_{\text {thermal-required }}}
$$

To estimate the annual amount of electricity consumed by the UK rendering industry ( $E_{\text {electric-required }}$ ), the average amount of electricity consumed by the six plants examined in the current study $\left(e_{\text {rendering }}\right.$ in $\mathrm{MJ} / \mathrm{kg} \mathrm{ABP}$ ) was multiplied by the annual mass of $\mathrm{ABP}$ processed by the UK rendering industry (Equation (5)).

The amount of electricity that could be produced by the UK rendering industry through the combustion of category $1 \mathrm{MBM}$ in FCB plants was calculated by multiplying the energy content of MBM by the annual amount of category 1 MBM available $\left(m_{M B M-a v a i}\right)$ and by assuming efficiency of conversion $\left(\eta_{F B C}\right)$ (Equation (6)) an efficiency of $18 \%$ taken from Yassin et al. [9].

$$
\begin{aligned}
& E_{\text {electric-required }}=m_{A B P-\text { procesed }} e_{\text {rendering }} \\
& E_{\text {electric-potential }}=\eta_{F B C} m_{M B M-a v a i} G C V_{M B M}
\end{aligned}
$$

where $G C V_{\text {MвM }}$ is the Gross Calorific Value of MBM (19.8 MJ/kg as indicated by the rendering companies participating in the current study).

The potential for the UK rendering industry to be self-sufficient in terms of electricity demand was expressed as a ratio, referred to as the self-sufficiency ratio for electricity $\left(S S R_{\text {electric }}\right)$ and according to Equation (7).

$$
S S R_{\text {electric }}=\frac{E_{\text {electric-potential }}}{E_{\text {electric-required }}}
$$

\section{Results and discussion}

\subsection{Energy consumption in the UK rendering industry}

The six plants included in the current study processed between 40 and $50 \%$ of the annual ABPs processed in the UK between 2006 and 2008 and hence represent a significant proportion of the UK rendering industry. Five of the six plants processed mammalian material and only one processed poultry material. Yields varied between the different plants, although within plants they were reasonably stable throughout the three years of the study, fig 3. The average yield of the 6 plants was 29\% protein meals and 15\% tallow (mass of rendered products expressed as percentage of mass of ABP processed). Lopez et al. [3] reported a yield of $23 \%$ protein meal and $28 \%$ tallow for beef ABP rendering in the US. The average yields detailed in the current study are significantly different to those reported in [3]. This may be due to differences in the water content of the ABPs processed.

The relationship between the amount of ABP processed and energy consumption by the 6 rendering plants used in the study is presented in fig. 4 . There is a strong linear relationship between the amount of ABP processed and 
the energy contained in combustion fuels $\left(\mathrm{R}^{2}=0.95\right)$, and a fairly strong linear relationship between the amount of $\mathrm{ABP}$ processed and electricity consumption $\left(\mathrm{R}^{2}=0.72\right)$.

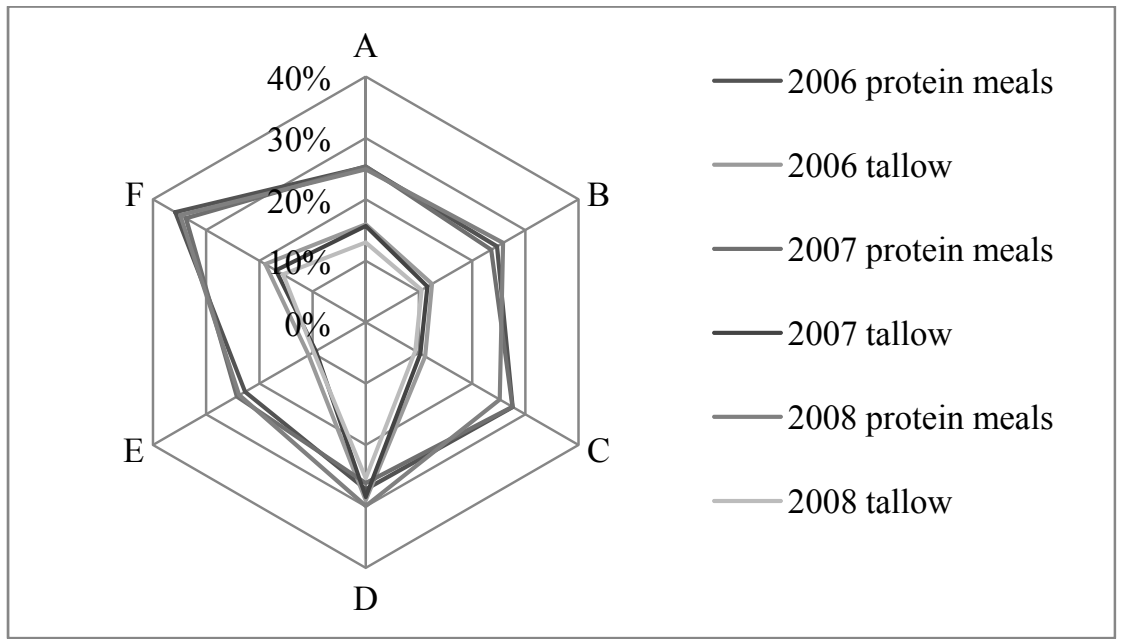

Figure 3: Annual yields of meat and bone meal and tallow (\% ABP processed) for 6 rendering plants (A to F) in the UK between the years 2006 and 2008.

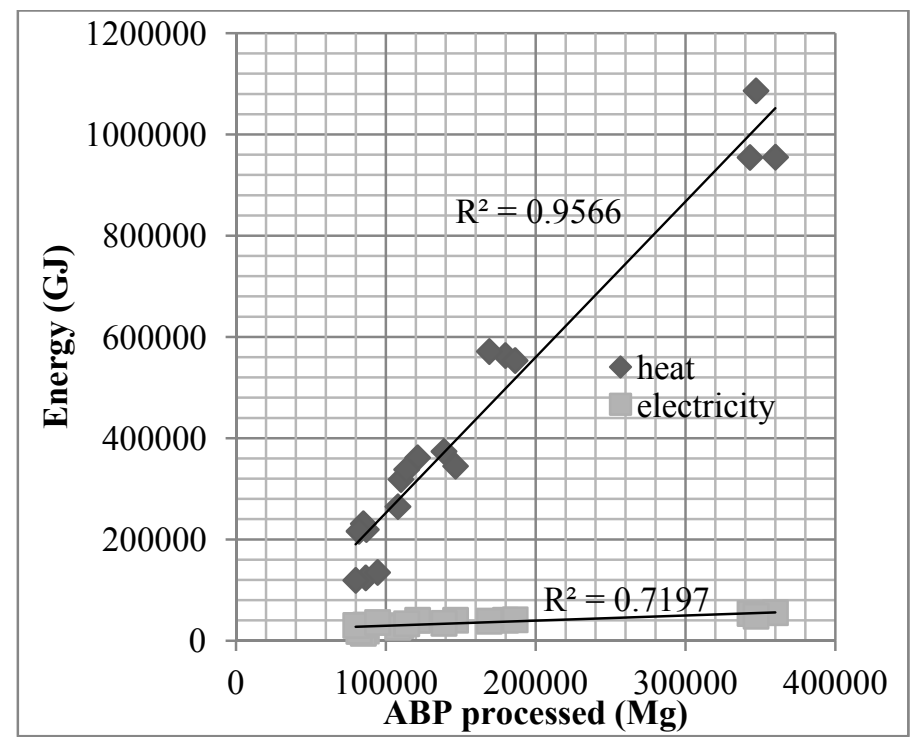

Figure 4: Relationship between the amount of animal by-product processed and energy consumption by 6 UK rendering plants between the years 2006 and 2008. 
The amount of energy contained in fuels to produce thermal energy for the rendering process ranged between 1.4 and $3.4 \mathrm{MJ} / \mathrm{kg}$ ABP processed for the six plants studied. Similarly, the amount of electricity used by the six rendering plants ranged between 0.1 and $0.4 \mathrm{MJ} / \mathrm{kg}$ ABP processed. Research by Lopez et al. [5] reported energy consumption by the US rendering industry of $2.8 \mathrm{MJ} / \mathrm{kg}$ ABP processed, of which $0.3 \mathrm{MJ} / \mathrm{kg} \mathrm{ABP}$ was in the form of electricity and 2.5 $\mathrm{MJ} / \mathrm{kg} \mathrm{ABP}$ was provided from the combustion of fuels. In contrast, Ramírez et al. [6] reported a figure for the European rendering industry of $1.6 \mathrm{MJ} / \mathrm{kg} \mathrm{ABP}$ processed. The values reported by the current study are in reasonable agreement with the values provided by Lopez et al. [3] and Ramírez et al. [6].

Regarding percentage of heat and electricity, for the six rendering plants included in the current study, electricity accounted for approximately $8 \%$ of energy with the remaining attributable to thermal energy. These values are in agreement with the figures reported by Lopez et al. [3] for the US rendering industry ( $9.4 \%$ for electricity).

The percentage of total thermal energy contained in tallow and natural gas used for the rendering process varied between plants, and between years as illustrated in fig 3. For example, plants B and F used only tallow, whilst plants $\mathrm{C}$ and E used significantly less tallow in 2007 and 2008 compared to 2006. The reasons for these variations probably reflect the relative cost of natural gas compared to alternative markets for tallow. The weighted average proportion of thermal process energy derived from tallow for the six plants was $76 \%$, with the remaining energy being derived from natural gas. Thus, the rendering industry already uses a relatively high proportion of thermal energy derived from tallow.

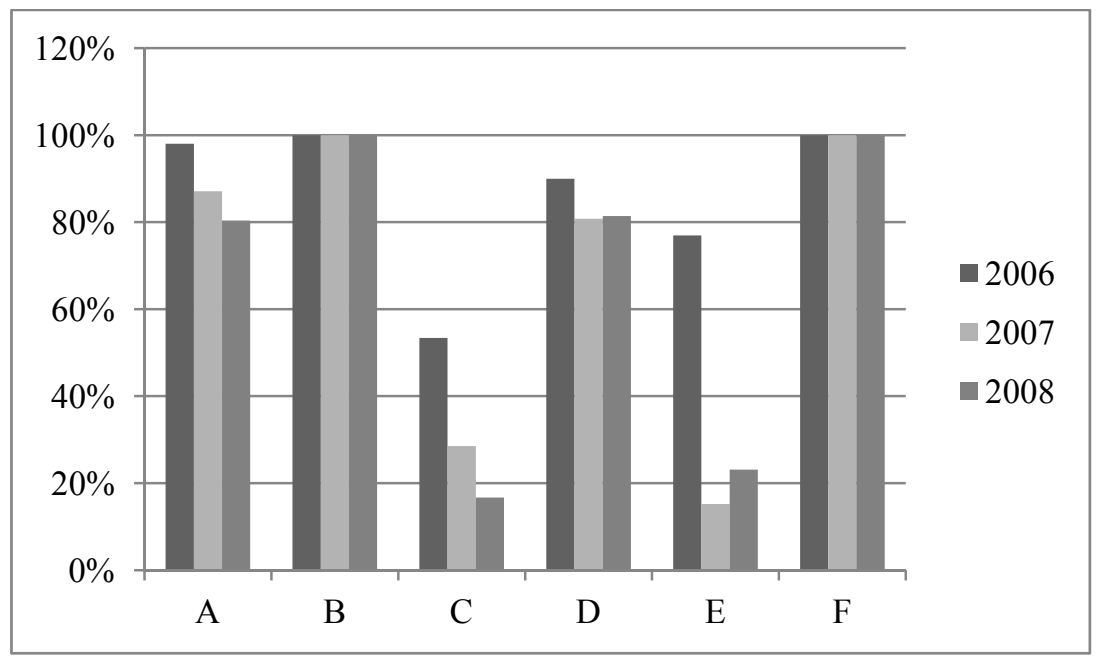

Figure 5: Annual percentage of thermal energy consumption derived from tallow for 6 UK rendering plants between 2006 and 2008. 


\subsection{Potential for energy self-sufficiency in the UK rendering industry}

The thermal energy requirement and the potential thermal energy production from tallow and the thermal self-sufficiency ratios for the UK rendering industry are provided in Table 1 for the years 2006, 2007, and 2008. The self-sufficiency ratios calculated are all greater than 1.0, indicating that the UK rendering industries thermal demand could be satisfied from the combustion of category 1 tallow. The generation of thermal energy from the combustion of category 1 tallow reduces the demand for finite fossil fuels, whilst additionally reducing greenhouse gas emissions because the biomass is associated with a short carbon cycle (Astrup et al. [2]). However alternative uses of category 1 tallow (e.g. biodiesel production) should be analysed to ascertain which uses of tallow provides the highest climate and financial benefits.

Table 2: The thermal energy requirement, the potential thermal energy production from category 1 tallow and the thermal self-sufficiency ratios for the UK rendering industry between 2006 and 2008.

\begin{tabular}{|c|c|c|c|}
\hline & 2006 & 2007 & 2008 \\
\hline$E_{\text {thermal-potential }}(\mathrm{PJ})$ & 6.8 & 6.5 & 6.8 \\
\hline$E_{\text {thermal-required }}(\mathrm{PJ})$ & 5.6 & 6.1 & 5.5 \\
\hline$S S R_{\text {thermal }}$ & 1.2 & 1.1 & 1.2 \\
\hline
\end{tabular}

The electricity requirement, and the potential electricity production from meat and bone meal and the electricity self-sufficiency ratios for the UK rendering industry are provided in Table 3 for the years 2006, 2007, and 2008. The selfsufficiency ratios calculated are greater than 1 , indicating that the rendering industry could be self-sufficient in terms of electricity. Electricity obtained from MBM has climate benefits in comparison to the use of British electricity, which is predominantly produced from the combustion of coal which is associated with high carbon emissions due to the properties of the fuel and the efficiency of the conversion process. MBM can also be used to produce heat in the cement industry; however as can be seen in fig. 3 this is not currently the main use. Greenhouse gas emissions from alternative uses of category 1 MBM should be analysed to ascertain which uses of category $1 \mathrm{MBM}$ provides the highest climate and financial benefits.

Table 3: The electricity requirement, the potential electricity production from category $1 \mathrm{MBM}$ and the electricity self-sufficiency ratios for the UK rendering industry between 2006 and 2008.

\begin{tabular}{|c|c|c|c|}
\hline & 2006 & 2007 & 2008 \\
\hline$E_{\text {electric-potential }}(\mathrm{PJ})$ & 1.2 & 1.1 & 1.1 \\
\hline$E_{\text {electric-required }}(\mathrm{PJ})$ & 0.5 & 0.5 & 0.4 \\
\hline$S S R_{\text {thermal }}$ & 2.7 & 2.3 & 2.3 \\
\hline
\end{tabular}




\section{Conclusion}

The UK rendering industry produces different categories of rendered products. Under current EU legislation category 1 rendered products are required to be destroyed by combustion. During the years 2006 to 2008 sufficient quantities of category 1 rendered products were produced to satisfy both the thermal energy and electricity requirements of the UK rendering industry. Rendered products are produced from ABPs which are unavoidable by-products of livestock production and meat processing; consequently, they do not carry an associated environmental burden. The UK rendering industry could be self-sufficient in energy use by utilising category 1 rendered products as biofuels.

\section{References}

[1] Commission Regulation (EC) No 1774/2002 of 3 Oct 2002 laying down health rules concerning animal by-products not intended for human consumption, Official Journal of the European Communities L109

[2] Astrup T., Moller J. \& Fruergaard T., Incineration and co-combustion of waste: accounting of greenhouse gases and global warming contributions. Waste Management Research, 27(8), pp. 789, 2009.

[3] Lopez D.E., Mullins J.C. \& Bruce D.A., Energy Life Cycle Assessment for the Production of Biodiesel from Rendered Lipids in the United States. Industrial \& Engineering Chemistry Research, 49(5), pp. 2419, 2010.

[4] Meeker D.L. \& Hamilton C.R. An overview of the rendering industry. Essential rendering, ed. D.L. Meeker, National Renderers Association: Alexandria, Virginia, pp. 1, 2006.

[5] NPL, Kaye \& Laby - tables of physical and chemical constants, http://www.kayelaby.npl.co.uk/

[6] Ramírez C.A., Patel M. \& Blok K., How much energy to process one pound of meat? A comparison of energy use and specific energy consumption in the meat industry of four European countries. Energy, 31(12), pp. 2047, 2006.

[7] Woodgate S.L., Personal communication, 11-30 April 2010, Director, Foodchain and Biomass Renewables Association Limited, Leicestershire, UK

[8] Woodgate S. \& van der Veen J., The role of fat processing and rendering in the European Union animal production industry. Biotechnol. Agron. Soc., 8(4), pp. 283, 2004.

[9] Yassin L., Lettieri P., Simons S.J.R. \& Germanà A., Techno-economic performance of energy-from-waste fluidized bed combustion and gasification processes in the UK context. Chemical Engineering Journal, 146(3), pp. 315, 2009. 